\title{
Hybrid multifunctional graphene/glass-fibre polypropylene composites
}

DOI:

10.1016/j.compscitech.2016.10.018

\section{Document Version}

Accepted author manuscript

Link to publication record in Manchester Research Explorer

\section{Citation for published version (APA):}

Papageorgiou, D. G., Kinloch, I. A., \& Young, R. J. (2016). Hybrid multifunctional graphene/glass-fibre polypropylene composites. Composites Science and Technology, 137, 44-51.

https://doi.org/10.1016/j.compscitech.2016.10.018

\section{Published in:}

Composites Science and Technology

\section{Citing this paper}

Please note that where the full-text provided on Manchester Research Explorer is the Author Accepted Manuscript or Proof version this may differ from the final Published version. If citing, it is advised that you check and use the publisher's definitive version.

\section{General rights}

Copyright and moral rights for the publications made accessible in the Research Explorer are retained by the authors and/or other copyright owners and it is a condition of accessing publications that users recognise and abide by the legal requirements associated with these rights.

\section{Takedown policy}

If you believe that this document breaches copyright please refer to the University of Manchester's Takedown Procedures [http://man.ac.uk/04Y6Bo] or contact uml.scholarlycommunications@manchester.ac.uk providing relevant details, so we can investigate your claim.

\section{OPEN ACCESS}




\title{
Hybrid multifunctional graphene/glass-fibre polypropylene composites
}

\author{
Dimitrios G. Papageorgiou*, Ian A. Kinloch, Robert J. Young \\ School of Materials and National Graphene Institute, University of Manchester, Oxford Road, \\ M13 9PL, United Kingdom
}

\begin{abstract}
The effect of the simultaneous addition, using a melt-mixing procedure, of glass fibres (GFs) and graphene in the form of graphene nanoplatelets (GNPs) upon the properties of polypropylene (PP) has been studied in detail. Composite samples containing GFs and GNPs alone were also prepared for comparative purposes. The crystalline microstructure of the composites was characterised by X-ray diffraction (XRD), while scanning electron microscopy (SEM) was used to study the interface between the matrix and the fillers. The orientation of the glass fibres was evaluated using SEM while polarized Raman spectroscopy was utilized to determinate the orientation of the GNPs in the composite samples. The mechanical properties of the composites were evaluated by tensile testing and it was found that the Young's modulus of the hybrid material is higher than that of the materials containing the fillers individually, showing an additive effect. Raman spectroscopy employed simultaneously with deformation of the composites was used to show that there was good interfacial stress transfer between the PP matrix and the GNPs. Finally, the thermal conductivity of the materials was measured and found to be significantly higher for the composites containing GNPs alone.
\end{abstract}

KEYWORDS: nanocomposites, polypropylene, graphite nanoplatelets, glass fibres, mechanical properties 


\section{INTRODUCTION}

The use of inorganic fillers as reinforcements for polymeric matrices has been a common strategy over the recent years for the development of a new generation of multifunctional materials [1-3]. Glass fibres (GF) are used to reinforce polymer composites for a number of applications due to their high tensile modulus and relatively low cost compared to carbon or aramid fibres [4-6]. Glass fibre-reinforced plastics (GFRP) have thus become a commodity material in automotive, aerospace and construction industries. Such GFRP materials do not, however, have sufficiently good mechanical properties for some applications, have a relatively high density compared to carbonbased systems, are electrically insulating and have relatively poor thermal conductivity.

The first isolation and identification of monolayer graphene by Geim and Novoselov and coworkers in 2004 [7] led to the development of few- and many-layer graphene for use as reinforcement in polymer-based nanocomposites [8-10]. In particular, the excellent electrical, thermal and mechanical properties of graphene have the potential to impart several desired characteristics upon the nanocomposites, such as improved thermal conductivity, durability, thermal stability and mechanical stiffness and strength. The preparation of few- and many-layer graphene in bulk quantities is still, however, a challenging task. Therefore both industry and academia are utilizing materials such as graphite nanoplatelets (GNP) that exhibit similar mechanical, thermal and electrical properties to graphene, but are significantly cheaper to produce. GNPs consist of short stacks graphene layers, while their lateral dimensions, aspect ratio, available surface area, morphology and properties make them effective for use as reinforcements [11-18].

A number of composite materials based on a combination of a number of different inorganic fillers have been developed over the last years. Such hybrid composites may involve quite diverse materials, while most of the literature reports refer to an additive (or synergistic) effect of both fillers, which acts to improve some of the final physicochemical properties of the composite material [19-26]. This method can be also used to balance some of the unavoidable disadvantages that a specific filler or process can attribute to the composite material. Pegoretti et 
al. [24] studied a hybrid filler combination similar to the one used in this paper, with the difference that the size of the GNP flakes was significantly smaller. Also the GFs in some samples were coated with graphite prior to mixing, while a compatibillizer was also used. The authors found that there was an increase of the elastic modulus of around 105\% in the samples with the hybrid filler, while the tensile strength was also increased by $16 \%$.

Herein, GNPs and GFs were incorporated in a PP matrix by melt mixing at different loadings both individually and together. The effect of each filler along with the hybrid combination (GF-GNP) on the mechanical properties of the materials has been evaluated by tensile testing and the orientation of the glass fibres was characterized using SEM. Raman spectroscopy was utilized for the evaluation of the spatial orientation of the GNPs, while an in situ bending procedure in conjunction with Raman spectroscopy used for the investigation of the stress transfer efficiency between the materials. X-ray diffraction (XRD) was used for the structural characterisation and scanning electron microscopy (SEM) to evaluate of the dispersion of the component fillers. Finally, the glass transition temperatures and thermal conductivities of the composites were also studied.

\section{EXPERIMENTAL DETAILS}

\subsection{Materials}

The polypropylene homopolymer employed was produced by Lyondellbasell under the commercial name, Moplen HP501L and exhibited a flow index of $6 \mathrm{~g} 10 \mathrm{~min}^{-1}$ and a melt density of $900 \mathrm{~kg} \mathrm{~m}^{-3}$. The glass-filled polypropylene was provided by Albis UK Ltd under the commercial name Altech PP-H A 2020/159 GF20 CP. This material was filled with $20 \mathrm{wt} \%$ of Eglass fibres (average length over $5 \mathrm{~mm}$ and average diameter of $15 \mu \mathrm{m}$ ), and had a melt density of $1040 \mathrm{~kg} \mathrm{~m}^{-3}$. Exfoliated graphite nanoplatelets (xGNP-25), produced by via the sulphuric intercalation of graphite, were obtained from XG Sciences (East Lansing, MI). The nanoplatelets had a mean platelet diameter of $25 \mu \mathrm{m}$ and an average thickness of 6-8 $\mathrm{nm}$ ( 20 graphene layers). 
The melt-mixing process was performed using a twin-screw extruder (Thermo Scientific HAAKE MiniLab micro compounder) at $190{ }^{\circ} \mathrm{C}$ and $100 \mathrm{rpm}$, and the mixing took place for 12 minutes. The pelletized product was further processed into dumbbell-shaped specimens by injection moulding (HAAKE MiniJet Piston Injection Moulding System, $T_{\text {cylinder }}=200{ }^{\circ} \mathrm{C}, T_{\text {mould }}=$ $70{ }^{\circ} \mathrm{C}$, pressure $=900$ bar, held for $12 \mathrm{~s}$ ).

The GNP-filled materials are coded PP-GNPx throughout the manuscript, where $\mathrm{x}$ is the filler content in wt $\%(x=5,10,20 \mathrm{wt} \%)$. Similarly, the samples filled with GF will be referred to as PP-GFx. For the production of hybrids, the material filled with $20 \mathrm{wt} \%$ GF (PP-GF20) was used as a masterbatch and the GNPs were added in the melt mixing process. This caused a proportional reduction in the GF content in the hybrid material. Three sets of samples were prepared, namely PP-GF19-GNP5, PP-GF18-GNP10, PP-GF16-GNP20. The exact amount of the fillers was additionally verified from the TGA residue of each sample (see respective results in Supplementary Information - Table S1). Finally, a sample filled with $10 \mathrm{wt} \%$ GF and $10 \mathrm{wt} \%$ GNP (PP-GF10-GNP10) was prepared for comparison purposes.

\subsection{Characterization of the PP composites}

$\mathrm{XRD}$ analysis was performed on the polymeric matrix and the nanocomposites using a Philips $\mathrm{X}^{\prime}$ pert Modular Powder Diffractometer (MPD) using $\mathrm{Cu} \mathrm{K}_{\alpha}$ radiation, a step size of $0.05^{\circ}$ and a step time of $1 \mathrm{~s}$, operating at $40 \mathrm{kV}$ and $30 \mathrm{~mA}$. Polarized Raman spectroscopy was employed in order to characterize the orientation of the graphene flakes in the polymer matrix using a backscattering geometry and a VV (vertical/vertical) combination of incident and scattered polarization. Stress-strain curves were obtained using dogbone shaped specimens in an Instron 4301 machine, under a tensile rate of $0.5 \mathrm{~mm} \mathrm{~min}^{-1}$ with a load cell of $5 \mathrm{kN}$, in accordance with ASTM D638. A contact extensometer was used during the testing procedure in order to obtain precise information on the deformation of the samples. Raman spectroscopy was used in situ during the deformation of PP composites to assess stress transfer at the GNP-PP interface. A 
Renishaw 1000 Raman microprobe system (Renishaw, UK) was used with a $15 \mathrm{~mW} \mathrm{He}-\mathrm{Ne}$ excitation laser and a laser spot size of about $2 \mu \mathrm{m}$. Scanning electron microscopy was performed on samples fractured after tensile testing with a FEI Sirion FEG-SEM. Dynamic mechanical thermal analysis (DMTA) (specimen size $35 \mathrm{~mm} \times 8 \mathrm{~mm} \times 1 \mathrm{~mm}$ ) was undertaken between -60 and $130{ }^{\circ} \mathrm{C}$ using a DMA Q800 analyzer (TA instruments). A heating rate of $3{ }^{\circ} \mathrm{C} / \mathrm{min}$ and a frequency of $1 \mathrm{~Hz}$ were employed under a nitrogen flow. The thermal conductivity of the materials was measured using a FOX50 (TA Instruments) apparatus, employing a dual thickness measurement cycle.

\section{RESULTS AND DISCUSSION}

\subsection{X-Ray Diffraction (XRD)}

The crystalline structure of the composite samples was evaluated by XRD and the results are presented in the Supplementary Information, Fig. S1. The neat PP sample had the characteristic peaks of isotactic polypropylene at $14.1^{\circ}, 16.9^{\circ}$ and $18.5^{\circ}$, which correspond to the principal reflections from the (110), (040) and (130) planes of the $\alpha$-crystals. Similarly, the polypropylene in all of the composite samples crystallized in the $\alpha$-form, indicating that the presence of the fillers did not affect the crystal structure of the matrix. The strong peaks from the presence of the GNPs are located at an angle of $2 \theta=26.4^{\circ}$ for all of the composite materials and corresponded to an interlayer spacing of $0.338 \mathrm{~nm}$. The crystallinities of the composite samples were determined

using the equation: $X_{\mathrm{c}}=\frac{A_{\mathrm{c}}}{A_{\mathrm{c}}+A_{\alpha}}$, where $A_{\mathrm{c}}$ and $A_{\alpha}$ are the areas under the crystalline peaks and amorphous halo, respectively. Prior to these calculations, a deconvolution of the diffractograms was performed. The crystallinities of the samples are listed in Table 1. For the samples filled with GNPs, the degree of crystallinity of the PP increased with increasing filler content, indicating the high nucleating ability of the nanoplatelets. The crystallinity of the PP-GF samples decreased, however, with increasing GF loading, suggesting that the GFs actually interrupted the linear crystallizable sequence of the macromolecular chains of polypropylene [27, 28]. Finally, it was 
found that the samples filled with the hybrid filler also exhibited a higher degree of crystallinity than the pure matrix.

Table 1. Crystallinities of the composite samples, as calculated from XRD

\begin{tabular}{|c|c|c|c|c|c|}
\hline Sample & $X_{\mathbf{c}}(\boldsymbol{\%})$ & Sample & $\boldsymbol{X}_{\mathbf{c}}(\boldsymbol{\%})$ & Sample & $\boldsymbol{X}_{\mathbf{c}}(\boldsymbol{\%})$ \\
\hline PP & 48.8 & PP & 48.8 & PP & 48.8 \\
\hline PP-GNP5 & 52.5 & PP-GF5 & 46.7 & PP-GF10-GNP10 & 52.6 \\
\hline PP-GNP10 & 54.1 & PP-GF10 & 45.4 & PP-GF19-GNP5 & 52.4 \\
\hline PP-GNP20 & 55.7 & PP-GF20 & 46.1 & PP-GF18-GNP10 & 55.2 \\
\hline & & & & PP-GF16-GNP20 & 57.5 \\
\hline
\end{tabular}

\subsection{Orientation of the fillers in composite materials}

The orientation of GNPs in composite materials can play a major role on the ultimate physicochemical properties since oriented fillers can form conductive pathways more easily, improve the energy dissipation during tensile testing and retard the growth of cracks during failure, increasing this way the modulus/strength [11]. Polarized Raman spectroscopy was utilized to evaluate the orientation of the GNPs in the samples [29] containing the maximum GNP content (PP-GNP20 and PP-GF16-GNP20), along with the sample filled with 10 wt $\%$ GF and GNP respectively (PP-GF10-GNP10). The polarized laser beam was aligned either perpendicular (in the $z$-direction) or parallel (in the $x$-direction) to the surface of the specimen which was then rotated on the microscope stage with a manual rotation platform. It should be noted that the $x$-direction is defined as the flow direction during the injection moulding procedure for the production of the dumbbell-type samples and that the direction of the incident and scattered polarization was the same (VV polarization). SEM was used for the evaluation of the orientation of the GFs in polished sections. The SEM images presented in Figure 4, along with the ones presented in Supplementary Information - Figure S2, indicate that the orientation of the GF was approximately random in both 
the PP-GF and PP-GF-GNP samples but the exact level of orientation could not be determined from the SEM micrographs.

From the results presented in Figure 1 for the PP-GF16-GNP20 sample, it was found that the intensity of the D band remained unchanged, as the sample was rotated about both the $x$ - and $z$ axes. This is an indication of random orientation of the GNP fillers in the composite samples, in agreement with similar studies from Valles et al. [30, 31] and Zhao et al. [32]. Similar behaviour was observed for the other samples under study as shown in the Supplementary Information-Fig. S3.
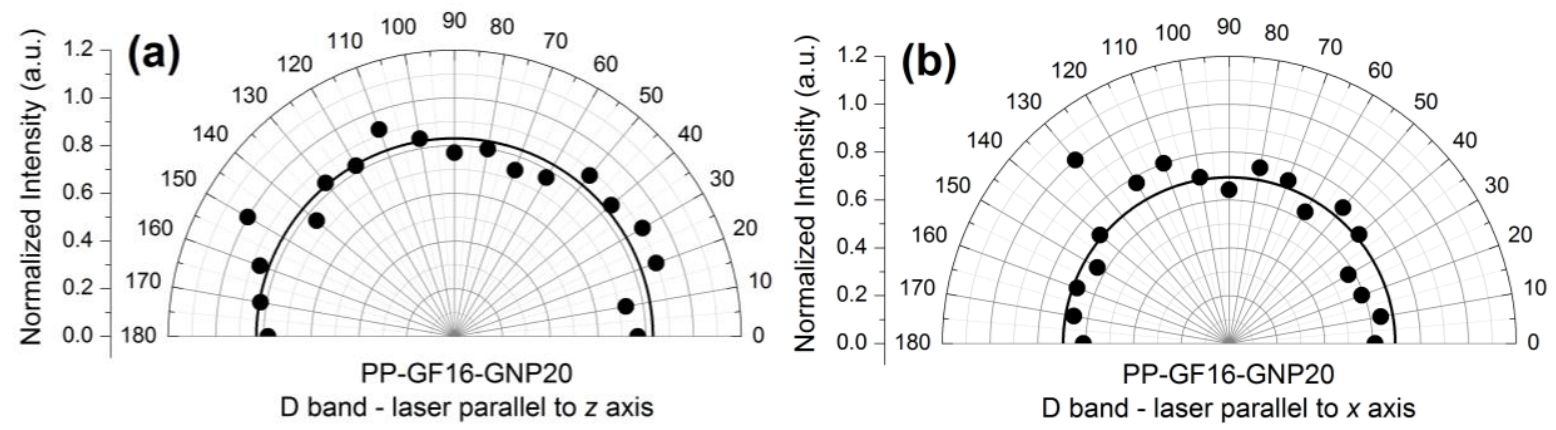

Figure 1. Variation of the Raman D-band intensity as a function of angle of specimen rotation, showing the random orientation of the graphite nanoplatelets in the PP-GF16-GNP20 sample. The curves are least squares fit to the experimental data. The results for other samples are given in the Supplementary Information.

\subsection{Mechanical Properties}

The mechanical properties of the samples filled with GF, GNP and the hybrid filler were evaluated by tensile testing (Figures 2 and 3). As expected, the addition of both the GNPs and GFs as a sole reinforcement increased the Young's modulus of the PP, with the GF giving a slight higher improvement than that of the GNP for a given loading by weight. It should be noted that GNPs exhibit lower density than the GFs, though, which actually means that the specific improvement is higher for the GNPs than the GFs. Both reinforcements approximately doubled the modulus of the 
matrix at $20 \mathrm{wt} \%$ loading, a result which is consistent with previously published results from our group for the case of few-layer graphene nanoplatelets in rigid polymers [30, 33].

It was also found that the fillers acted additively in the hybrid system, with the specimen with the maximum GF and GNP content (PP-GF16-GNP20), exhibiting a Young's modulus three times higher than the neat PP (Figure 3a). The presence of GNPs at the interface between the PP and GFs may lead to better interfacial stress transfer between the PP and GFs.
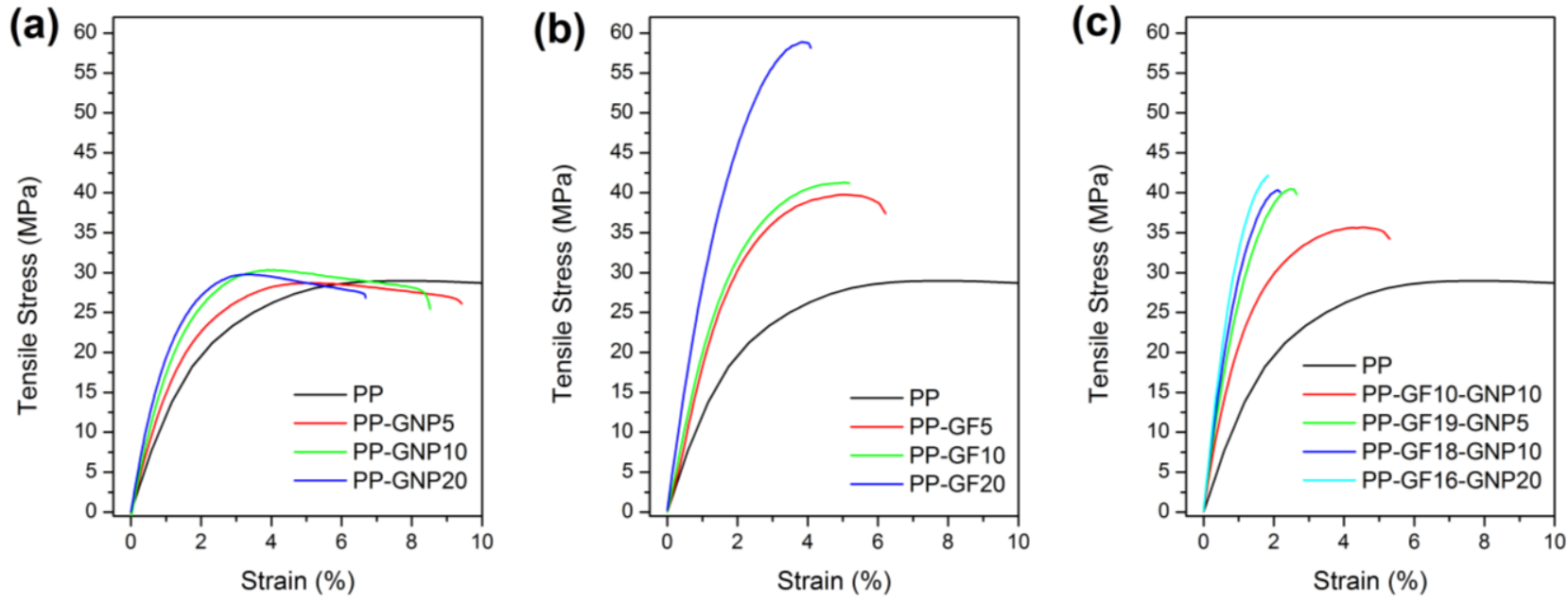

Figure 2. Stress-strain curves of PP and composite materials; (a) PP-GNP, (b) PP-GF, (c) PP-GFGNP

Moreover, the fracture stress decreased slightly upon the addition of the GNPs, while the samples filled solely with GFs exhibited a significantly higher strength at break than neat PP, with the sample filled with $20 \mathrm{wt} \%$ GFs having a fracture stress almost double that of the matrix. The fracture stress of the hybrid GF-GNP materials was also found to increase with filler loading (Figure 3b) with the maximum value falling between that of the two fillers used separately. It was also found that in general, the addition of the fillers reduced the failure strain of the PP with a larger reduction being found for the addition of the GFs compared to the GNPs. 
(a)

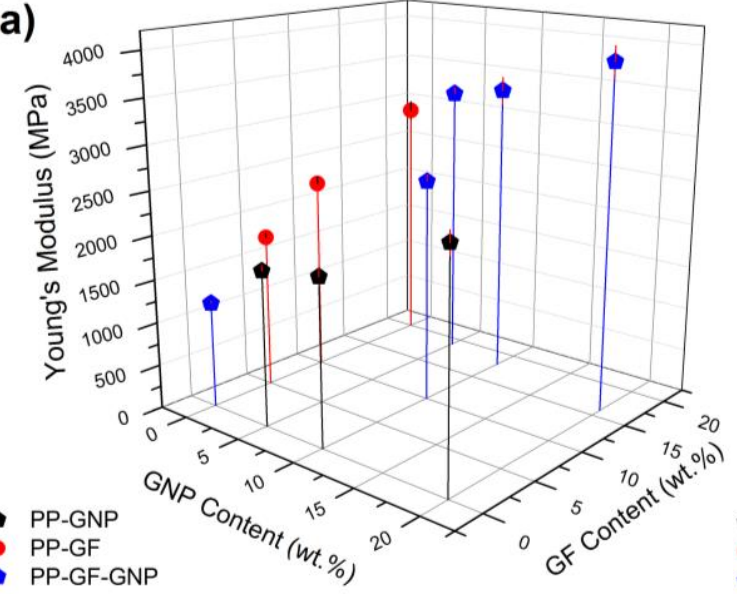

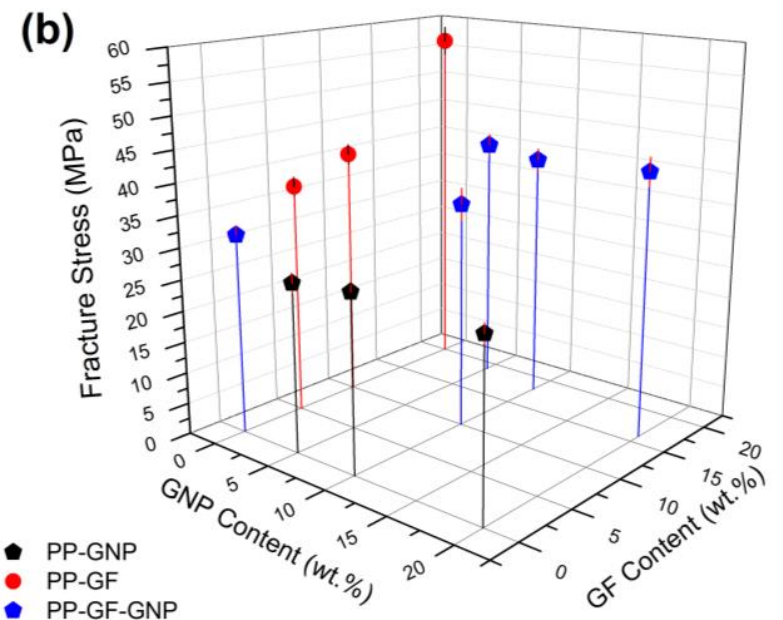

(b)

- PP-GF-GNP

Figure 3. Results for the (a) tensile modulus and (b) fracture stress of the PP and the composite samples

\subsection{Scanning Electron Microscopy (SEM)}

The fracture surfaces produced during the tensile testing experiments were characterised using SEM to evaluate the degree of dispersion of the fillers and investigate the failure processes. For the GNP-reinforced system, the GNPs were well dispersed in the samples at low loadings but at the highest loading ( $20 \mathrm{wt} \%$ GNP) the GNPs were aggregated with the presence of both the aggregates on the fracture surface and voids (Figure 4a). The GFs were found to be well-dispersed at all loadings and that there was a range of pull-out lengths for the individual fibres. It appears that the orientation of the fillers was random throughout the fracture surfaces with the case for the GNPs being confirmed earlier by Raman spectroscopy, while for GFs additional SEM images are provided in the Supplementary Information - Figure S2, which provide some indications but cannot be considered absolute indicators for the randomness of the fibres in 3 dimensions. The improved interfacial strength of the PP-GF-GNP set of samples resulted in some of the GNPreinforced PP remaining on the surface of the GFs (Figure 4c). In contrast, the surface of the GFs in the PP-GF samples was not coated with polymer (Figure $4 \mathrm{~b}$ ). 


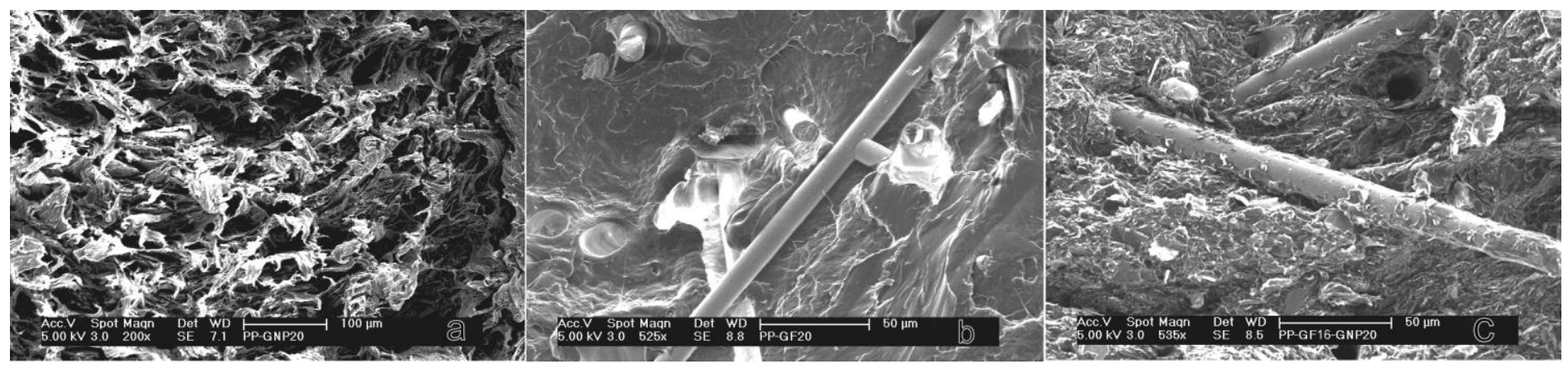

Figure 4. SEM images of fractured composite samples: (a) PP-GNP20, (b) GFs in the PP-GF sample (c) GFs coated with PP and GNPs in the PP-GF16-GNP20 specimen.

\subsection{Calculation of the effective modulus of the fillers}

The modulus of elasticity of a polymer composite containing a single filler can be modelled by the modified rule of mixtures (MROM) as [34]

$$
E_{\mathrm{c}}=E_{\mathrm{p}} V_{\mathrm{p}} \eta_{\mathrm{o}} \eta_{1}+E_{\mathrm{m}} V_{\mathrm{m}}
$$

where $E_{\mathrm{c}}$ is the modulus of the composite, $V_{\mathrm{p}}$ and $V_{\mathrm{m}}$ are the volume fraction of the filler and matrix, $E_{\mathrm{p}}$ and $E_{\mathrm{m}}$ are the modulus of the filler and matrix, $\eta_{1}$ is the length parameter that is used for the evaluation of the stress transfer at the filler-matrix interface for particles with small lateral dimensions and $\eta_{\mathrm{o}}$ is the Krenchel orientation factor [35]. The filler volume fraction was calculated from the well-known relationship: $V_{\mathrm{f}}=\frac{W_{\mathrm{f}} / \rho_{\mathrm{f}}}{W_{f} / \rho_{\mathrm{f}}+W_{\mathrm{m}} / \rho_{\mathrm{m}}}$, where $w_{\mathrm{f}}$ is the weight fraction of the filler, while $\rho_{\mathrm{f}}$ and $\rho_{\mathrm{m}}$ are the densities of the filler and the matrix respectively. For the case of the hybrid filler, the equation was adjusted in order to take into account the presence of both fillers in the matrix volume.

The effective modulus $E_{\text {eff }}$ of the fillers in the composites is less than their inherent, individual particle modulus values as a result of their orientation within the matrix and their finite length and it can be given by the equation $E_{\mathrm{eff}}=E_{\mathrm{p}} \eta_{\mathrm{l}} \eta_{\mathrm{o}}$. The orientation of the GNPs is random as shown by polarised Raman spectroscopy and observed by SEM, while it was found to be approximately random for the glass fibres. The Krenchel factor for the random orientation of the 
nanoplatelets is equal to $\eta_{\mathrm{o}} \approx 8 / 15$ [36] and $\eta_{\mathrm{o}} \approx 1 / 5$ for the fibres [35]. Moreover, in our calculations we assumed that there was perfect stress transfer; therefore the length parameter $\eta_{1}$ is equal to 1 . The effective modulus can also be calculated by obtaining the gradient of $E_{\mathrm{c}}$ versus volume fraction graph (Figure 5). The effective modulus of the fillers $E_{\text {eff }}$ was found equal to $15 \mathrm{GPa}$ for the GNPs and $22 \mathrm{GPa}$ for the GFs and the relevant Krenchel factors allow the values of $E_{\mathrm{p}}$ to be determined for the two types of filler. Assuming $\eta_{1}=1$, the value of $E_{\mathrm{p}}$ for the GNPs is $28.1 \mathrm{GPa}$ and that for the GFs is $110 \mathrm{GPa}$. The relatively low value for the GNPs is probably the result of the material being relatively thick $[37,38]$ and aggregation effects. The equivalent modulus value for the glass fibres is $110 \mathrm{GPa}$, which is higher than the literature values of $75-80 \mathrm{GPa}[39,40]$. This fact leads us to the conclusion that the orientation of the fibres is not completely random. If we consider that the effective modulus of the fibres is equal to the literature value $\left(E_{\text {eff }}=75 \mathrm{GPa}\right)$, then the orientation factor is calculated to be $\eta_{o}=0.29$, which lies between random $3 \mathrm{D}\left(\eta_{0}=1 / 5\right)$ and random in-plane $\left(\eta_{0}=3 / 8\right)$ [35]. Hence, it appears that the overall orientation of the glass fibres is somewhere between random 3D and random in-plane.
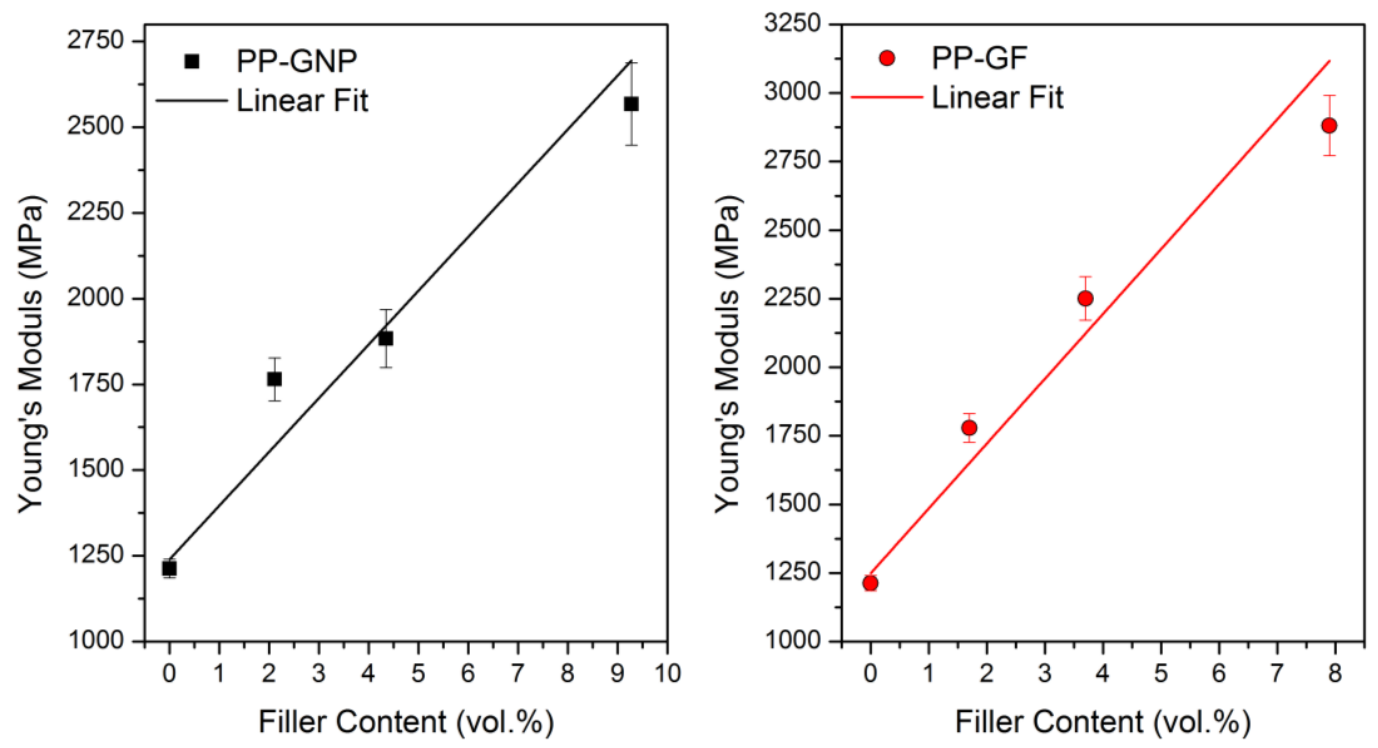

Figure 5. Variation of modulus with filler content and linear fits for the use in the modified rule of mixtures. 
The Young's modulus of the polymer composites under study can be extended to a threephase system as:

$$
E_{\mathrm{c}}=E_{\mathrm{GNP}} V_{\mathrm{GNP}} \eta_{\mathrm{o}(\mathrm{GNP})} \eta_{\mathrm{l(GNP})}+E_{\mathrm{GF}} V_{\mathrm{GF}} \eta_{\mathrm{o}(\mathrm{GF})} n_{1(\mathrm{GF})}+E_{\mathrm{m}} V_{\mathrm{m}}
$$

The MROM assumes that no interaction is taking place between the components of the system and each filler behaves as an individual material in the hybrid. By applying the effective modulus of the fillers obtained earlier, the results for the hybrid system can be seen in Figure 6. The curvature of the theoretical line originates from the fact that for the hybrid samples, there are fluctuations in the GNP and GF individual filler contents, affecting the linearity of the plot. At low filler volumes (the term "filler" here refers to the sum of the volumes of GF and GNP) the experimental values are very close to the MROM values, indicating that for low loadings an additive effect may take place between the components of the system. In fact the data point for a total volume fraction of around 10 vol\% lies slightly above the MROM line indicating that there at this loading there may be some synergism between the fillers. With increasing filler loading, the formation of aggregates appears to hinder the further improvement of the modulus and a levelling off occurs, which is not accounted for in the MROM equation. For this reason, the MROM fails to predict accurately the moduli of the materials with the highest filler content, even though the simulated value falls within the experimental error. The dashed lines in Figure 6 represent the two-phase MROM from the PPGNP and PP-GF set of samples, based on the values of the effective modulus obtained earlier. As expected, the values of the 3-phase MROM lie between the ones of the 2-phase MROM for GF and GNP composites. 


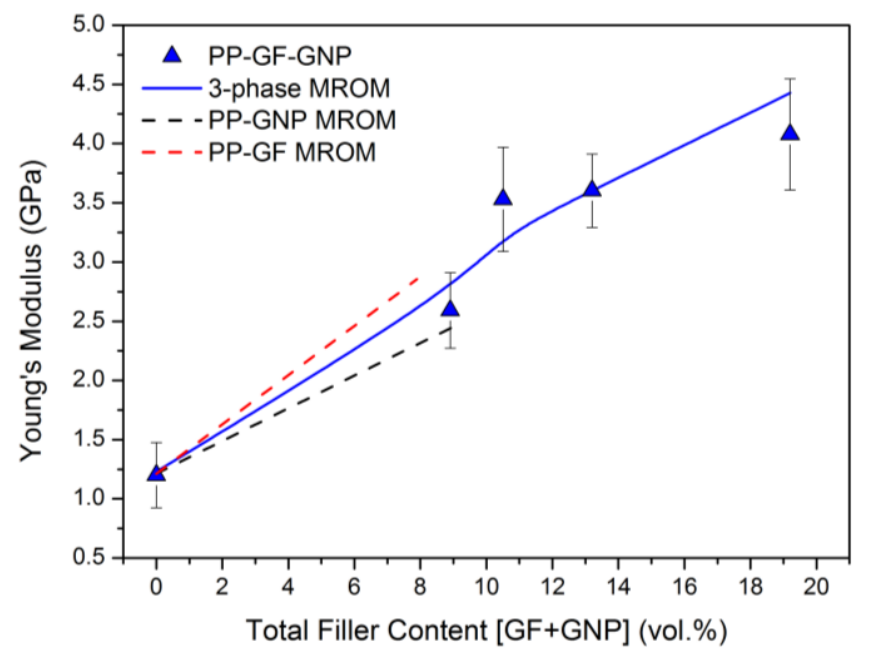

Figure 6. Experimental results for the modulus of the hybrid materials and fit with the modified rule of mixtures (MROM).

\subsection{Stress-Induced Raman Band Shifts}

The Raman spectra for all samples were recorded initially (Supplementary Information-Figure S4) and subsequently Raman spectroscopy was employed in order to study the stress transfer between the filler and the matrix by monitoring the shift of the 2D Raman band of the graphite nanoplatelets under strain. The specific procedure developed by Young and coworkers [41, 42] enables quantification of the stress transfer efficiency between the components of the system, since the slope of the downshift of the characteristic graphitic Raman bands is proportional to the effective modulus of the reinforcement, which includes the length factor. A four point bending rig was used in order to bend rectangular beams of the composites, which were placed under the laser spot. The beams were deformed up to $0.6 \%$ strain in $0.05 \%$ intervals, while a strain gauge attached to the beams was used for the monitoring of the strain. The polarization of the laser beam was always parallel to the tensile axis.

The downshift of the 2D bands that was observed in all the composites under study reveals that the load was transferred from the matrix to the filler during the bending procedure. The slope of the plot of the position of the band against strain can be taken as an indication of the efficiency 
of stress transfer [41]. The characteristic plots for PP-GNP20 and PP-GF16-GNP20 only are presented for brevity (Figure 7), while the respective plots for rest of the materials can be found in Supplementary Information - Figure S5. Two tests were performed for each composition and the results are presented in Table 2. In the case of uniform strain, as assumed by the MROM, it is predicted [37] that the slope of such plots will be independent of the volume fraction of filler. It can also be seen that the set of samples containing the hybrid filler shows slightly higher shift rates than the samples filled solely with GNP which is another indication that stress transfer was more efficient in these materials. This is in accordance with the results from the mechanical testing, as these samples exhibited higher modulus values than the PP-GNP ones. Furthermore, the slight decrease of the shift rate with increasing the filler content, that has been observed in the literature $[43,44]$, is most probably due to aggregation of the GNPs.
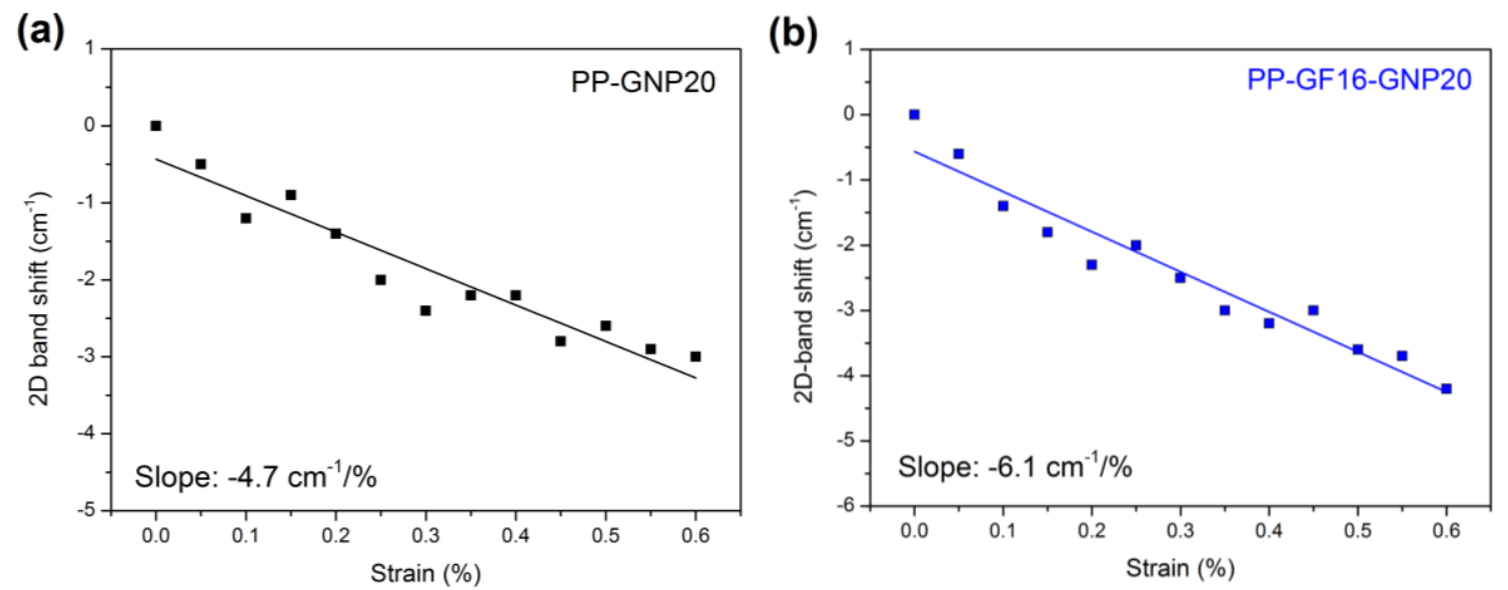

Figure 7. Shift of the Raman 2D band with applied strain for the samples filled with (a) $20 \mathrm{wt} \%$ GNP and (b) 16 wt.\% GF and 20 wt.\% GNP

The slopes of the lines in Figure 7 and listed in Table 2, are $\sim-5 \mathrm{~cm}^{-1} / \%$ for the GNP-filled materials and $\sim-6 \mathrm{~cm}^{-1} / \%$ for the hybrid and enable the effective Young's modulus of the GNPs to be determined. [38] Since the band shift rate for the monolayer graphene with Young's modulus of $1050 \mathrm{GPa}$ is $-60 \mathrm{~cm}^{-1} / \%$, values of modulus of $87 \mathrm{GPa}$ and $105 \mathrm{GPa}$ are derived from these band shift rates. Moreover, since the spectra were obtained using a polarised laser beam these values do 
not need to be corrected for orientation effects. The modulus values derived from the band shifts for the GNPs are a factor of three higher than those determined from the stress-strain data. This may be because the Raman data were obtained from individual $25 \mu \mathrm{m}$ diameter GNPs using a laser beam of the order of $2 \mu \mathrm{m}$ diameter, following local GNP deformation, whereas the stress-strain data were the result of deformation of GNPs in the entire specimen.

Table 2. Average Raman 2D Band Shift Rates for the composite samples filled with GNP

\begin{tabular}{|c|c|c|c|}
\hline Sample & Shift Rate $\left(\mathbf{c m}^{-1} / \%\right)$ & Sample & Shift Rate $\left(\mathbf{c m}^{-1} / \%\right)$ \\
\hline PP-GNP5 & $-5.3 \pm 0.5$ & PP-GF19-GNP5 & $-6.9 \pm 0.8$ \\
\hline PP-GNP10 & $-4.9 \pm 0.4$ & PP-GF18-GNP10 & $-6.3 \pm 0.7$ \\
\hline PP-GNP20 & $-4.7 \pm 0.5$ & PP-GF16-GNP20 & $-6.1 \pm 1.3$ \\
\hline & & PP-GF10-GNP10 & $-5.9 \pm 0.9$ \\
\hline
\end{tabular}

\subsection{Dynamic Mechanical Analysis}

During the DMA experiments, a gradual increase in the $T_{\mathrm{g}}$ was observed in the case of the nanocomposites filled with GNP, with the sample filled with $20 \mathrm{wt} \%$ GNP exhibiting a $T_{\mathrm{g}}$ that is $11 \mathrm{~K}$ higher than that of the neat PP (Figure 8). This is an evidence of the anti-plasticization effect of the GNPs which decreases the segmental mobility and the steric hindrance of polymer chains between the filler particles. In contrast, the presence of glass fibres lowered the $T_{\mathrm{g}}$ of the matrix, with the sample filled with $20 \mathrm{wt} \%$ GF possessing a $T_{\mathrm{g}}$ that is $3 \mathrm{~K}$ lower than PP, which can be attributed to the higher mobility on the polymer chains of the matrix. This observation can be associated with the lower crystallinity of the PP-GF samples, as was confirmed by XRD. For the samples with the hybrid filler, an antagonistic effect between the two fillers takes place, with the GNP being more active and affecting the $T_{\mathrm{g}}$ more significantly, giving an overall increase, compared to the matrix. The volume restriction phenomenon that is taking place due to the presence of both fillers at high concentrations hinders once again the mobility of the PP chains and leads to the increase of the glass transition. The plots of $\tan \delta$ against temperature for each set of 
samples, along with a table listing the $T_{\mathrm{g}}$ for each sample can be seen in Supplementary Information - Figure S6, Table S2. Moreover, the plot of the loss modulus $\left(E^{\prime \prime}\right)$ against temperature can also be seen in Supplementary Information - Figure S7. The shifts of the peaks is analogous to the glass transition fluctuations based on the filler content, while the loss modulus is also higher than the matrix, as a result of the increase in internal friction that enhances the dissipation of energy [45].

The flexibility of the interface between the filler and the matrix plays a major role on the glass transition temperature of the composite materials [46]. From the findings presented here, it can be deduced that the interface formed in the PP-GF set of materials is more flexible than the one formed for the PP-GNP. Moreover, the physical presence of GFs and GNPs, in the samples containing both fillers, leads to an interface with lower flexibility than the PP-GNP samples.

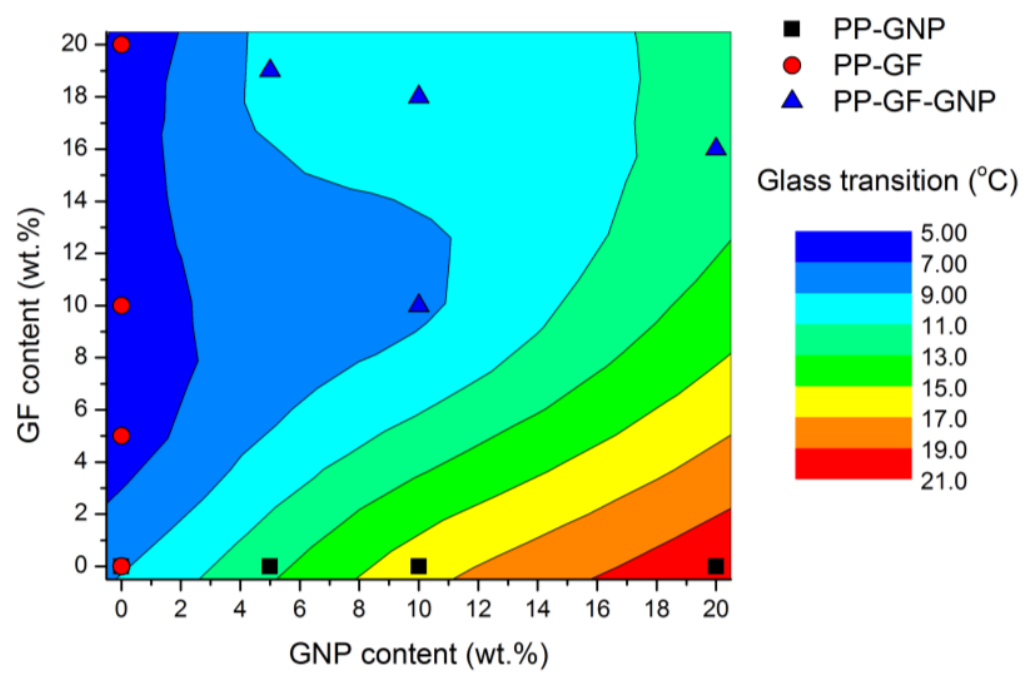

Figure 8. Contour plot of the glass transition temperatures, $T_{\mathrm{g}}$, of PP and composites (the solid symbols represent the respective filler content).

\subsection{Thermal Conductivity}

The large surface area and large aspect ratio of the GNP flakes enables the formation of a good interface between them and the matrix and the formation of bridges of percolating networks, which is a key factor in obtaining high thermal conductivity in composite materials [47]. The phonon transfer is facilitated from the random bridges of GNP pathways and thus the conductivity 
increases significantly. The thermal conductivity of the PP samples filled with GNP was four times higher than the matrix at the maximum loading (Figure 9). In contrast, there was an increase of $70 \%$ for the sample with the highest loading of glass fibres (PP-GF20). Interestingly, the samples filled with the hybrid fillers showed a slightly higher conductivity, even though glass fibres exhibit relatively low inherent conductivity values. The interconnectivity of glass fibres and their coating with polymer and GNP flakes [48] could be one of the reasons for the observation of this increase, since an interconnected network between the fillers is possibly formed within the polymeric matrix. In this study, the increase compared to neat polypropylene was 5 times higher for the sample with the highest filler content.

The rule of mixtures has been applied to the experimental data in order to evaluate the contribution of the conducting phase (filler), since this model assumes perfect contact between the particles [49]. The simple equation that describes the ROM is the following:

$\kappa_{\mathrm{c}}=\kappa_{\mathrm{f}} V_{\mathrm{f}}+\kappa_{\mathrm{m}} V_{\mathrm{m}}$

where $\kappa_{\mathrm{c}}, \kappa_{\mathrm{f}}$ and $\kappa_{\mathrm{m}}$ are the thermal conductivities of the composite, the filler and the matrix. In an analogy with the procedure followed for the tensile modulus, the effective conductivity of the fillers was initially calculated by linear fitting the experimental data from the set of samples with the individual fillers. For the PP-GNP, the effective thermal conductivity of the GNP flakes was calculated equal to $10 \mathrm{Wm}^{-1} \mathrm{~K}^{-1}$, which is in good agreement with the results of Xiang and Drzal [50] and provides an indication that the fillers may have formed a percolating network in the PPGNP samples. Regarding the GFs, the effective conductivity was calculated to be equal to 2.35 $\mathrm{Wm}^{-1} \mathrm{~K}^{-1}$, a value higher than the numbers reported in the literature $\left(1.2-1.5 \mathrm{Wm}^{-1} \mathrm{~K}^{-1}[48]\right)$. Finally, for the hybrid samples, the 3-phase $\mathrm{ROM}\left(\kappa_{\mathrm{c}}=\kappa_{\mathrm{GNP}} V_{\mathrm{GNP}}+\kappa_{\mathrm{GF}} V_{\mathrm{GF}}+\kappa_{\mathrm{PP}} V_{\mathrm{PP}}\right)$ takes into account the contributions of both GF and GNP and it can be seen in Figure 9 that the curve is quite close to most of the experimental values, except for the sample filled with 5 wt.\% GNP and 19 wt.\% GF (volume fraction 10.5\%). 


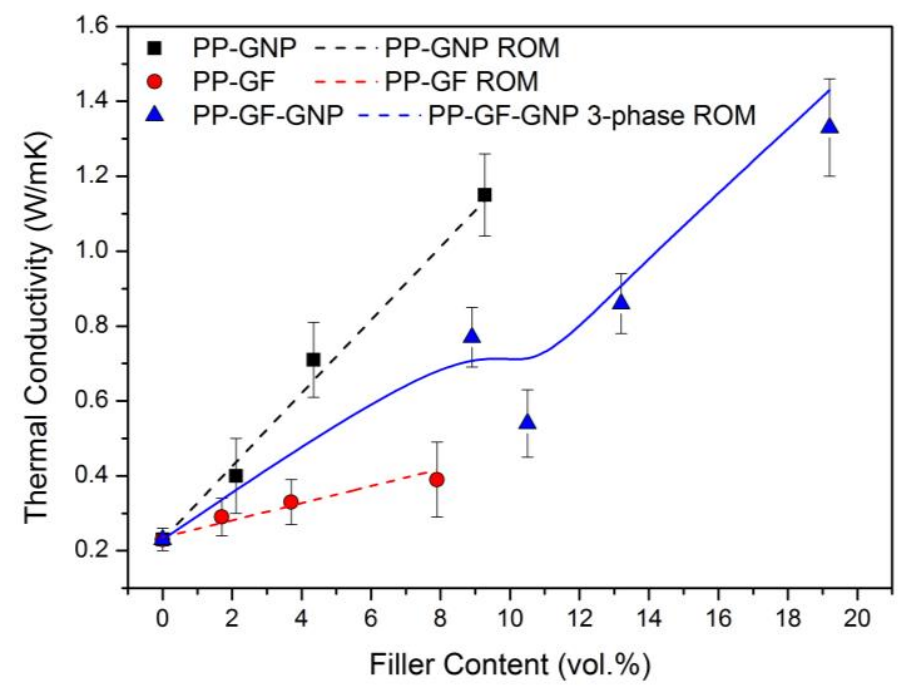

Figure 9. Thermal conductivity of the composite samples. The filler content (vol\%) of the PP-GFGNP samples (blue triangles) refers to the total filler content from the sum of both GF and GNP. The reader is referred to the web version for better interpretation of the curves.

\section{CONCLUSIONS}

The effect of the incorporation of graphite nanoplatelets and short glass fibres, both separately and in combination, upon the structure and mechanical properties of polypropylene has been studied in detail. It has been found that the addition of the glass fibres decreases both the degree of crystallinity and glass transition temperature of the polypropylene whereas both of these parameters are increased significantly upon the addition of the graphite nanoplatelets, improving the thermal properties of the material.

The addition of both of these fillers to polypropylene increases the Young's modulus of the polymer to a similar extent for a given volume fraction and there is some evidence from Raman spectroscopy and from the use of a 3-phase modified rule of mixtures that, when added together, the two fillers may give better reinforcement by acting additively. The addition of the glass fibres is found to increase the fracture stress but reduces the failure strain of the polymer whereas the addition of the graphite nanoplatelets causes less reduction in the failure strain. Finally, the presence of glass fibres in the polypropylene is found to have little effect upon the thermal 
conductivity of the polymer whereas the addition of the graphene nanoplatelets is found to increase it by more than a factor of five.

\section{ASSOCIATED CONTENT}

Supplementary Information including SEM images, Raman and XRD spectra of all samples, the mass residue of each sample, the orientation of the GNP-containing materials based on the intensity of the $\mathrm{D}$ band and the rotation angle, the 2D band shift versus stain curves, the tan $\delta$ and loss modulus versus temperature curves can be found online.

\section{AUTHOR INFORMATION}

Corresponding author: dimitrios.papageorgiou@manchester.ac.uk

\section{ACKNOWLEDGEMENTS}

This research has been supported by funding from the European Union Seventh Framework Programme under grant agreement n604391 Graphene Flagship and the EPSRC (award no. EP/I023879/1). The authors are grateful to Albis UK Ltd for the supply of materials and helpful discussions.

\section{REFERENCES}

[1] Ray SS, Okamoto M. Polymer/layered silicate nanocomposites: a review from preparation to processing. Progress in polymer science. 2003;28(11):1539-1641.

[2] Alexandre M, Dubois P. Polymer-layered silicate nanocomposites: preparation, properties and uses of a new class of materials. Materials Science and Engineering: R: Reports. 2000;28(1-2):163.

[3] Moniruzzaman M, Winey KI. Polymer nanocomposites containing carbon nanotubes. Macromolecules. 2006;39(16):5194-5205. 
[4] Kornmann X, Rees M, Thomann Y, Necola A, Barbezat M, Thomann R. Epoxy-layered silicate nanocomposites as matrix in glass fibre-reinforced composites. Composites Science and Technology. 2005;65(14):2259-2268.

[5] Vlasveld D, Parlevliet P, Bersee H, Picken S. Fibre-matrix adhesion in glass-fibre reinforced polyamide-6 silicate nanocomposites. Composites Part A: applied science and manufacturing. 2005;36(1):1-11.

[6] Wichmann MH, Sumfleth J, Gojny FH, Quaresimin M, Fiedler B, Schulte K. Glass-fibrereinforced composites with enhanced mechanical and electrical properties-benefits and limitations of a nanoparticle modified matrix. Engineering Fracture Mechanics. 2006;73(16):2346-2359.

[7] Novoselov KS, Geim AK, Morozov SV, Jiang D, Zhang Y, Dubonos SV, et al. Electric field in atomically thin carbon films. Science. 2004;306(5696):666-669.

[8] Potts JR, Dreyer DR, Bielawski CW, Ruoff RS. Graphene-based polymer nanocomposites. Polymer. 2011;52(1):5-25.

[9] Papageorgiou DG, Kinloch IA, Young RJ. Graphene/elastomer nanocomposites. Carbon. 2015;95:460-484.

[10] Kim H, Abdala AA, MacOsko CW. Graphene/polymer nanocomposites. Macromolecules. 2010;43(16):6515-6530.

[11] Kalaitzidou K, Fukushima H, Drzal LT. Multifunctional polypropylene composites produced by incorporation of exfoliated graphite nanoplatelets. Carbon. 2007;45(7):1446-1452.

[12] Fukushima H. Graphite nanoreinforcements in polymer nanocomposites2003.

[13] Kalaitzidou K, Fukushima H, Drzal LT. Mechanical properties and morphological characterization of exfoliated graphite-polypropylene nanocomposites. Composites Part A: Applied Science and Manufacturing. 2007;38(7):1675-1682.

[14] Li J, Kim J-K. Percolation threshold of conducting polymer composites containing 3D randomly distributed graphite nanoplatelets. Composites Science and Technology. 2007;67(10):2114-2120.

[15] Zheng W, Wong SC. Electrical conductivity and dielectric properties of PMMA/expanded graphite composites. Composites Science and Technology. 2003;63(2):225-235.

[16] Yu A, Ramesh P, Sun X, Bekyarova E, Itkis ME, Haddon RC. Enhanced thermal conductivity in a hybrid graphite nanoplatelet-carbon nanotube filler for epoxy composites. Advanced Materials. 2008;20(24):4740-4744.

[17] Mack JJ, Viculis LM, Ali A, Luoh R, Yang G, Hahn HT, et al. Graphite nanoplatelet reinforcement of electrospun polyacrylonitrile nanofibers. Advanced Materials. 2005;17(1):77-80. [18] Kostagiannakopoulou C, Fiamegkou E, Sotiriadis G, Kostopoulos V. Thermal Conductivity of Carbon Nanoreinforced Epoxy Composites. Journal of Nanomaterials. 2016;2016:12. 
[19] Thwe MM, Liao K. Durability of bamboo-glass fiber reinforced polymer matrix hybrid composites. Composites Science and Technology. 2003;63(3):375-387.

[20] Manders P, Bader M. The strength of hybrid glass/carbon fibre composites. Journal of Materials Science. 1981;16(8):2233-2245.

[21] Shen X-J, Pei X-Q, Liu Y, Fu S-Y. Tribological performance of carbon nanotube-graphene oxide hybrid/epoxy composites. Composites Part B: Engineering. 2014;57:120-125.

[22] Lee S-B, Choi O, Lee W, Yi J-W, Kim B-S, Byun J-H, et al. Processing and characterization of multi-scale hybrid composites reinforced with nanoscale carbon reinforcements and carbon fibers. Composites Part A: Applied Science and Manufacturing. 2011;42(4):337-344.

[23] Pedrazzoli D, Pegoretti A. Silica nanoparticles as coupling agents for polypropylene/glass composites. Composites Science and Technology. 2013;76:77-83.

[24] Pedrazzoli D, Pegoretti A, Kalaitzidou K. Synergistic effect of graphite nanoplatelets and glass fibers in polypropylene composites. Journal of Applied Polymer Science. 2015;132:41682. [25] Pedrazzoli D, Pegoretti A. Expanded graphite nanoplatelets as coupling agents in glass fiber reinforced polypropylene composites. Composites Part A: Applied Science and Manufacturing. 2014;66:25-34.

[26] Kong K, Hejda M, Young RJ, Eichhorn SJ. Deformation micromechanics of a model cellulose/glass fibre hybrid composite. Composites Science and Technology. 2009;69(13):22182224.

[27] Rahman NA, Hassan A, Yahya R, Lafia-Araga R, Hornsby P. Polypropylene/glass fiber/nanoclay hybrid composites: morphological, thermal, dynamic mechanical and impact behaviors. Journal of Reinforced Plastics and Composites. 2012;31(18):1247-1257.

[28] Li Q, Zheng G, Dai K, Xie M, Liu C, Liu B, et al. $\beta$-transcrystallinity developed from the novel ringed nuclei in the glass fiber/isotactic polypropylene composite. Materials Letters. 2011;65(14):2274-2277.

[29] Chen Y, Xi J, Dumcenco DO, Liu Z, Suenaga K, Wang D, et al. Tunable band gap photoluminescence from atomically thin transition-metal dichalcogenide alloys. ACS nano. 2013;7(5):4610-4616.

[30] Vallés C, Abdelkader AM, Young RJ, Kinloch IA. The effect of flake diameter on the reinforcement of few-layer graphene-PMMA composites. Composites Science and Technology. 2015;111:17-22.

[31] Vallés C, Beckert F, Burk L, Mülhaupt R, Young RJ, Kinloch IA. Effect of the C/O ratio in graphene oxide materials on the reinforcement of epoxy- based nanocomposites. Journal of Polymer Science Part B: Polymer Physics. 2015. 
[32] Zhao X, Zhang Q, Chen D, Lu P. Enhanced Mechanical Properties of Graphene-Based Poly(vinyl alcohol) Composites. Macromolecules. 2010;43(5):2357-2363.

[33] Valles C, Abdelkader AM, Young RJ, Kinloch IA. Few layer graphene-polypropylene nanocomposites: the role of flake diameter. Faraday Discussions. 2014;173(0):379-390.

[34] Young RJ, Lovell PA. Introduction to Polymers, Third Edition. Boca Baton, Florida, USA: CRC Press; 2013.

[35] Li ZL, Young RJ, Wilson NR, Kinloch IA, Valles C, Li Z. Effect of the orientation of graphene-based nanoplatelets upon the Young's modulus of nanocomposites. Composites Science and Technology. 2016;123:125-133.

[36] Li Z, Young RJ, Wilson NR, Kinloch IA, Vallés C, Li Z. Effect of the orientation of graphene-based nanoplatelets upon the Young's modulus of nanocomposites. Composites Science and Technology. 2016;123:125-133.

[37] Young RJ, Kinloch IA, Gong L, Novoselov KS. The mechanics of graphene nanocomposites: A review. Composites Science and Technology. 2012;72(12):1459-1476.

[38] Gong L, Young RJ, Kinloch IA, Riaz I, Jalil R, Novoselov KS. Optimizing the Reinforcement of Polymer-Based Nanocomposites by Graphene. ACS nano. 2012;6(3):2086-2095.

[39] Thomason JL, Vlug MA. Influence of fibre length and concentration on the properties of glass fibre-reinforced polypropylene: 1. Tensile and flexural modulus. Composites Part A: Applied Science and Manufacturing. 1996;27(6):477-484.

[40] Fu SY, Lauke B, Mäder E, Yue CY, Hu X. Tensile properties of short-glass-fiber- and shortcarbon-fiber-reinforced polypropylene composites. Composites Part A: Applied Science and Manufacturing. 2000;31(10):1117-1125.

[41] Young R, Eichhorn S. Deformation mechanisms in polymer fibres and nanocomposites. Polymer. 2007;48(1):2-18.

[42] Cooper CA, Young RJ, Halsall M. Investigation into the deformation of carbon nanotubes and their composites through the use of Raman spectroscopy. Composites Part A: Applied Science and Manufacturing. 2001;32(3-4):401-411.

[43] Li Z, Young RJ, Wang R, Yang F, Hao L, Jiao W, et al. The role of functional groups on graphene oxide in epoxy nanocomposites. Polymer. 2013;54(21):5821-5829.

[44] Li Z, Young RJ, Kinloch IA. Interfacial Stress Transfer in Graphene Oxide Nanocomposites. ACS Applied Materials \& Interfaces. 2013;5(2):456-463.

[45] Hameed N, Sreekumar P, Francis B, Yang W, Thomas S. Morphology, dynamic mechanical and thermal studies on poly (styrene-co-acrylonitrile) modified epoxy resin/glass fibre composites. Composites Part A: Applied Science and Manufacturing. 2007;38(12):2422-2432. 
[46] Li Z, Wang R, Young RJ, Deng L, Yang F, Hao L, et al. Control of the functionality of graphene oxide for its application in epoxy nanocomposites. Polymer. 2013;54(23):6437-6446. [47] Gojny FH, Wichmann MHG, Fiedler B, Kinloch IA, Bauhofer W, Windle AH, et al. Evaluation and identification of electrical and thermal conduction mechanisms in carbon nanotube/epoxy composites. Polymer. 2006;47(6):2036-2045.

[48] Weidenfeller B, Höfer M, Schilling FR. Thermal conductivity, thermal diffusivity, and specific heat capacity of particle filled polypropylene. Composites Part A: Applied Science and Manufacturing. 2004;35(4):423-429.

[49] Ruiz-Vargas CS, Zhuang HL, Huang PY, van der Zande AM, Garg S, McEuen PL, et al. Softened Elastic Response and Unzipping in Chemical Vapor Deposition Graphene Membranes. Nano Lett. 2011;11(6):2259-2263.

[50] Xiang J, Drzal LT. Investigation of exfoliated graphite nanoplatelets (xGnP) in improving thermal conductivity of paraffin wax-based phase change material. Solar Energy Materials and Solar Cells. 2011;95(7):1811-1818. 